\title{
IPSS Risk Score
}

National Cancer Institute

\section{Source}

National Cancer Institute. IPSS Risk Score. NCI Thesaurus. Code C139295.

The total score for myelodysplastic syndrome progression that considers the percentage of blasts in bone marrow (scored on a scale from zero to 2), chromosome abnormalities (scored from zero to 1), and the patient's blood counts (scored as zero or $0.5)$. 